\title{
Redes cooperativas de pesquisa em saúde: descrição e análise do uso de um instrumento de coordenação em um instituto público de pesquisa em biomedicina
}

\author{
Cooperative health research networks: a description and analysis \\ of a coordination tool in a public biomedical research institute
}

\author{
Márcia de Oliveira Teixeira ${ }^{1}$ \\ Carlos José Saldanha Machado ${ }^{2}$ \\ Ana Tereza Pinto Filipecki ${ }^{1}$ \\ Bianca Antunes Cortes ${ }^{1}$ \\ Helena Espellet Klein ${ }^{2}$
}

${ }^{1}$ Programa de Vocação Científica, Laboratório de Iniciação Científica, Escola Politécnica de Saúde Joaquim Venâncio,

Fundação Oswaldo Cruz. Av. Brasil 4365, Manguinhos.

21045-900 Rio de Janeiro

RJ.marciat@fiocruz.br

${ }^{2}$ Laboratório de Pesquisa em Ciência, Tecnologia e Inovação em Saúde,

Instituto de Comunicação e Informação Científica e

Tecnológica em Saúde,

Fundação Oswaldo Cruz.

\begin{abstract}
The purpose of this article is to describe and analyze the dynamics of cooperative public health research networks, and their utilization as the principal coordination instrument for a technological development program in a public health research institution. It begins with a few methodological considerations in regard to carrying out surveys and systemizing and analyzing data. Next a brief conceptual explanation of cooperative networks is made along with the characteristics of the program. Then the cooperative networks are described and analyzed, observing the relationships between the various actors that dynamize the program, the presence of IT and communications tools, and the sharing of the techno-scientific base among the projects of cooperative networks. The article concludes by interlacing some considerations about the local appropriation of a conceptual techno-scientific organizational model - the cooperative networks. The creation of a data bank of empirical data, and of local concepts and categories for analyses are considered to be decisive factors for increasing the knowledge acquired through sociology and anthropology about research best practices and administration of biomedical research.
\end{abstract}

Key words Cooperative research networks, Technological development, Public research institution, Collaborative research, Biomedicine
Resumo O objetivo deste artigo édescrever e analisar a dinâmica de redes cooperativas de pesquisa em saúde como principal instrumento de coordenação de um programa de desenvolvimento tecnológico em saúde em uma instituição pública de pesquisa. Iniciamos com algumas considerações metodológicas sobre as técnicas utilizadas no levantamento, sistematização e análise dos dados. Em seguida fazemos uma breve exposição conceitual sobre as redes cooperativas, acompanhada da caracterização do programa. Descrevemos e analisamos posteriormente as redes cooperativas, observando as relações entre os diferentes atores que dinamizam o programa, a presença de ferramentas de tecnologia da informação e comunicação e o compartilhamento da base técnico-científica entre os projetos das redes cooperativas. Concluimos o artigo tecendo algumas considerações sobre a apropriação local do modelo conceitual de organização da pesquisa técnico-científica - as redes cooperativas. Consideramos que a constituição de um acervo de dados empíricos, de conceitos e de categorias locais de análise contribuirá, decisivamente, para a ampliação do conhecimento gerado pela sociologia e pela antropologia sobre as práticas de pesquisa e gestão da pesquisa em biomedicina.

Palavras-chave Redes cooperativas de pesquisa, Desenvolvimento tecnológico em saúde, Instituição pública de pesquisa, Pesquisa colaborativa, Biomedicina 


\section{Introdução}

Nos últimos sete anos, a necessidade de conectar a discussão da ciência e da tecnologia (C\&T) à política nacional de saúde ganhou expressão no setor saúde, revertendo, assim, a sua posição secundária no processo da reforma sanitária embora a ciência e a tecnologia figurem como componentes da política nacional de saúde ${ }^{1,2}$. Neste sentido, o objetivo deste artigo é descrever e analisar a dinâmica de redes cooperativas de pesquisa em saúde utilizadas como instrumento de coordenação por um programa institucional de fomento ao desenvolvimento tecnológico em saúde em uma instituição pública de pesquisa (IPP). Interessa-nos reunir elementos sobre o modo de apropriação local de um modelo conceitual de organização da pesquisa experimental e da colaboração praticado entre equipes de pesquisa e instituições internacionalmente. Assim, selecionamos uma instituição (Fundação Oswaldo Cruz) que, em sua área de atuação, é a única com abrangência nacional; e um programa (Programa de Desenvolvimento Tecnológico em Insumos em Saúde) afinado com os princípios contemporâneos da organização da $\mathrm{C} \& \mathrm{~T}^{3,4}$, isto é, com a pesquisa científica colaborativa, a indução de áreas e temas de pesquisa, além do uso de redes como modo de coordenação da pesquisa.

$\mathrm{O}$ artigo está dividido em cinco partes. Iniciamos com uma breve exposição conceitual sobre as redes cooperativas como dispositivos de coordenação da pesquisa científica colaborativa. Em seguida, fazemos algumas considerações metodológicas sobre as técnicas utilizadas no levantamento, sistematização e análise dos dados. $\mathrm{Na}$ terceira seção, após uma descrição resumida da Fundação Oswaldo Cruz, caracterizamos o programa privilegiando seus objetivos, a fonte de financiamento, as áreas temáticas escolhidas, os critérios de seleção dos projetos, as redes constituídas, os projetos apoiados, as unidades da Fiocruz envolvidas, além do mecanismo de coordenação interna do programa. Na quarta seção, à luz da discussão conceitual, descrevemos e analisamos as redes cooperativas, observando as relações entre os diferentes atores que dinamizam o programa, a presença de ferramentas de tecnologia da informação e comunicação, além do compartilhamento da base técnico-científica entre os projetos das redes cooperativas. Nessa etapa, utilizamos basicamente o material sistematizado a partir das entrevistas e da observação empírica in loco. Concluímos o artigo tecendo algumas considerações sobre a apropriação local do modelo conceitual de organização da pesquisa técnico-científica - as redes cooperativas. Consideramos que a constituição de um acervo de dados empíricos, de conceitos e de categorias locais de análise contribuirá para a ampliação do conhecimento gerado pela sociologia e pela antropologia sobre as práticas e a gestão da pesquisa em biomedicina.

\section{Conceituação e contextualização das redes cooperativas}

A emergência das redes cooperativas, dos consórcios de pesquisa, das alianças estratégicas, dos centros de excelência e das plataformas tecnológicas se dá no contexto da disseminação da pesquisa científica colaborativa nos últimos trinta anos ${ }^{3,5-}$ ${ }^{7}$. Na literatura, a intensificação da pesquisa colaborativa relaciona-se com a multiplicação de projetos que requerem grandes volumes de recursos e a expertise em múltiplas áreas de conhecimento, além de instrumentações complexas e diversificadas, incorporadas ou não a equipamentos ${ }^{5,6}$. A colaboração entre dois parceiros cede lugar à colaboração entre grandes equipes (teamwork). Donald Beaver 8,9 considera que "teamwork or giant collaborations, represents a new paradigm for the organizational structure of research"8. Outro aspecto salientado pela literatura especializada é a dispersão de colaborações entre diferentes instituições ${ }^{3,10}$, constituindo colaborações multi-institucionais entre duas ou mais instituições ${ }^{5}$. Nos últimos trinta anos, as colaborações multi-institucionais ou não se revestem ainda de uma outra característica, isto é, o envolvimento de duas ou mais disciplinas - colaborações multidisciplinares $^{10}$. Para muitos autores, as colaborações multidisciplinares e multi-institucionais estão na base de novos campos do conhecimento e das disciplinas científicas ${ }^{6,10,11}$.

A expansão dessa forma de pesquisa colaborativa deve-se em grande parte à ação de organismos como o National Science Foundation (NSF) e a União Europeia ${ }^{3,10}$. Cummings e Kiesler ${ }^{10}$ lembram como as colaborações multidisciplinares e multi-institucionais são, em geral, associadas ao aumento da probabilidade de produção de inovações técnico-científicas; e como essa relação está na base da intensificação e da dispersão geográfica das colaborações. Diane Sonnenwald ${ }^{12}$ entende a colaboração científica como uma forma de produção de conhecimentos técnico-científicos que suporta interações orientadas para áreas e objetivos comuns, enquan- 
to Pirró e Longo e Oliveira ${ }^{7}$ destacam como os projetos multi-institucionais apresentam objetivos, prazos e metas bem definidos. Beaver ${ }^{8}$ enumera, entre as vantagens da colaboração científica envolvendo grandes equipes de trabalho, o aumento da produtividade por meio do processamento paralelo e do desenvolvimento de vários projetos simultaneamente, além da formação de novos pesquisadores.

As colaborações multidisciplinares e multiinstitucionais lançam mão de outros instrumentos de coordenação além da organização em rede. Vários autores ${ }^{5,10,12}$ citam reuniões, cursos, supervisão de pós-doutorado, workshops ou conferências, além de uma variedade de ferramentas de tecnologias da informação e comunicação, como e-mail, mensagens instantâneas, telefone e videoconferência ${ }^{10}$. A magnitude da colaboração ${ }^{5}$ implica mudanças nos instrumentos de coordenação e na intensificação da associação de mais de um instrumento ${ }^{10}$. Esses instrumentos constituem-se em variáveis recorrentes nas análises das colaborações científicas ${ }^{3,5,8,10}$.

Recorre-se ao conceito de rede para descrever a implementação de formas de coordenação apropriadas entre os atores e para analisar a mecânica complexa das interações entre atores heterogêneos (laboratórios de pesquisa, firmas, consumidores). No Brasil, as redes cooperativas constituíram-se em um dispositivo da política de ciência e tecnologia praticada pelos atores que integram o Sistema Nacional de Ciência, Tecnologia e Inovação ${ }^{7}$.

\section{Metodologia}

O estudo de natureza qualitativa foi realizado de julho de 2006 a junho de 2008 com base em diferentes técnicas, tais como entrevistas abertas não diretivas, análise de documentos diversos e observação etnográfica de reuniões do Programa de Desenvolvimento Tecnológico em Insumos em Saúde (PDTIS) ${ }^{13}$.

A identificação, o levantamento e a análise de documentos estenderam-se por todo o período de realização da pesquisa e tomaram como fonte secundária relatórios dos congressos internos da Fiocruz de 2002 e 2005; os Planos Quadrienais da Fiocruz de 2001 a 2005 e de 2005 a 2009, bem como a revisão realizada em agosto de 2007; os relatórios das Conferências de Ciência, Tecnolo- gia e Inovação de 2001 e de 2005; atas da Câmara Técnica de Pesquisa e Desenvolvimento Tecnológico de 2001 a 2005; o Relatório da Conferência de C\&T em Saúde (2004), com destaque para a Agenda de Pesquisa do Ministério da Saúde; a Lei da Inovação e os decretos que a regulamentam; atas de reunião das redes do PDTIS; relatórios de avaliação do PDTIS; planejamento anual do PDTIS; Manual de Organização do PDTIS de 2003 e 2004.

A partir da análise das atas da Câmara Técnica de Pesquisa e Desenvolvimento Tecnológico e do Relatório do Congresso Interno da Fiocruz de 2002, compusemos uma primeira listagem de atores da pesquisa para a realização de entrevistas abertas semiestruturadas. Nela figuram o coordenador do PDTIS, gestores da Vice-Presidência de Pesquisa e Desenvolvimento Tecnológico (VPPDT), diretores das unidades de produção de vacinas e medicamentos da Fiocruz e pesquisadores que participaram das discussões preliminares e do processo de implantação do PDTIS. Outros atores foram posteriormente identificados e selecionados a partir da realização das primeiras entrevistas.

Uma segunda rodada de entrevistas concentrou-se nos coordenadores das redes cooperativas e nos gerentes de projetos do PDTIS. Realizamos um total de 32 entrevistas com duração de 45 a 120 minutos. As informações levantadas foram complementadas com observações das reuniões de avaliação anual do programa, ocorridas em 2007 e no primeiro semestre de 2008 e organizadas por redes cooperativas. A escolha deve-se ao fato de a literatura sobre pesquisa científica colaborativa considerar as reuniões de avaliação como um dos mecanismos de coordenação ${ }^{3-5,10,14}$.

Para a realização das entrevistas e das observações, consideramos um conjunto de variáveis identificadas a partir da revisão de literatu$\mathrm{ra}^{3,5,6,8,10}$. Assim, demos ênfase: (1) às relações entre as diferentes instâncias da estrutura do PDTIS (coordenação geral, coordenadores de rede e gerentes de projetos); (2) às formas e aos mecanismos de interação entre as equipes de pesquisa de uma determinada rede; (3) à presença de ferramentas de tecnologia da informação e comunicação que intensificam a colaboração no interior de uma rede ou entre as redes cooperativas do PDTIS; (4) ao compartilhamento da base técnico-científica no interior de uma rede específica ou entre as redes cooperativas do PDTIS. 


\section{Caracterização da Fiocruz e do programa}

A análise dos documentos subsidiou a caracterização da Fiocruz e do programa, sendo que algumas informações foram complementadas por meio das entrevistas realizadas com os gestores.

A Fiocruz é a maior IPP em saúde do Brasil atuando na pesquisa científica e no desenvolvimento tecnológico nas áreas da biomedicina e das ciências sociais e humanas em saúde com ênfase na pesquisa em doenças infectoparasitárias e em saúde pública. Ela congrega um conjunto de quinze unidades distribuídas por seis cidades em cinco regiões: Rio de Janeiro (RJ), Belo Horizonte (MG), Curitiba (PR), Salvador (BA), Recife (PE) e Manaus (AM).

Desde 2001 a Fiocruz promove redirecionamentos em sua política de pesquisa e de desenvolvimento tecnológico. Entre outras iniciativas, estruturou em 2002 o Programa de Desenvolvimento Tecnológico em Insumos (PDTIS) ${ }^{15}$. O intuito era fortalecer a tecnologia e introduzir a inovação como componente dessa política por meio do reordenamento da organização da pesquisa até então fortemente centrada no padrão acadêmico para uma comprometida com as prioridades do MS e as necessidades técnico-científicas do setor produtivo em saúde ${ }^{15-19}$. Essas medidas guardam uma estreita relação com o contexto nacional nos últimos 15 anos no tocante à ciência e tecnologia e às atividades de pesquisa e desenvolvimento tecnológico, marcado pela emergência das noções de inovação e de sistema nacional de inovação ${ }^{18}$.

O PDTIS tem por objetivo estimular a pesquisa aplicada e o desenvolvimento tecnológico de produtos e processos com impacto na saúde pública e no controle de doenças infecto-parasitárias, como vacinas, kits para o diagnóstico, fármacos, medicamentos e produtos para o controle de veto$r^{20}{ }^{20}$. Entre seus objetivos, estabelece a formação de redes cooperativas para otimização de recursos e articulação das etapas que compõem o Desenvolvimento Tecnológico através da interação das equipes de diferentes unidades ${ }^{21}$. Para tanto, pretende favorecer-se da existência de duas plantas industriais no interior da Fiocruz dedicadas à produção de insumos em saúde.

O documento ${ }^{15}$ lançado pela VPPDT, responsável pela estruturação e coordenação do programa, definiu três áreas estratégicas a partir das quais redes cooperativas deveriam ser formadas - (1) Pró-Insumos; (2) Genoma Funcional; (3) Modelos Biológicos e de Triagem - e considerou como prioritárias as seguintes doenças infecto- parasitárias de impacto na saúde pública nacional: tuberculose, hanseníase, Aids, dengue e febre amarela, malária, infecções virais (respiratórios e outras), hepatites, infecções bacterianas, doenças de Chagas, leishmaniose, filariose, leptospirose. O PDTIS nasceu alinhado à política da Organização Mundial da Saúde (OMS) de fomento à pesquisa de tecnologias com doenças negligenciadas pela grande indústria farmacêutica e para as quais não se dispõe de estratégias e insumos eficientes e eficazes para controle e tratamento; bem como à própria tradição da Fiocruz na pesquisa com doenças infectoparasitárias ${ }^{22}$.

Em 2002, a VPPDT enviou cartas-convites para grupos de pesquisa da Fiocruz, com projetos em diferentes estágios de desenvolvimento, para participarem de workshops sobre desenvolvimento tecnológico de vacinas, medicamentos, genômica e proteômica e insumos diagnósticos - temas que originaram as quatro redes cooperativas do PDTIS. Em seguida, lançou editais para a submissão de cartas de intenção a uma das quatro redes cooperativas. Os editais estabeleceram as áreas e os temas induzidos pelo PDTIS. Esse processo ocorreu entre os meses de abril (workshop) e maio (cartas de intenção). A implementação dos projetos ocorreu em junho, após assinatura de carta-compromisso pelo gerente do projeto.

As redes cooperativas estão distribuídas pelos campi da Fiocruz no Rio de Janeiro, em Belo Horizonte, Curitiba, Salvador e Recife. Na Tabela 1, apresentamos a distribuição dos projetos entre as unidades técnico-científicas da Fiocruz. Adotamos aqui o mesmo critério definido pelo PDTIS, qual seja: o projeto é vinculado à unidade do seu gerente.

Quanto à natureza administrativa das unidades participantes, temos, além das técnico-científicas dedicadas à pesquisa em biomedicina, as duas unidades de produção (Bio-Manguinhos e Farmanguinhos) e uma das duas unidades da Fiocruz dedicadas à pesquisa e à assistência em saúde (Ipec). A Rede de Insumos Diagnósticos é a que apresenta melhor distribuição entre as unidades. Nas demais redes há uma concentração de projetos no IOC (27). Ele e o CPqRR são as únicas unidades com participação em todas as redes. O IOC é a primeira das unidades organizacionais da Fundação Oswaldo Cruz e foi responsável em 2007 por $48 \%$ da produção científica da Fiocruz publicada em periódicos nacionais e internacionais indexados ${ }^{20}$.

O acompanhamento dos projetos ocorre por meio de reuniões anuais organizadas pela $\mathrm{Ge}$ - 
Tabela 1. Número de projetos por rede cooperativa e por unidade da Fiocruz.

\begin{tabular}{|c|c|c|c|c|c|}
\hline Unidade & Campus & $\begin{array}{l}\text { Genômica e } \\
\text { Proteômica } \\
\text { Aplicada }\end{array}$ & $\begin{array}{c}\text { Insumos } \\
\text { diagnósticos }\end{array}$ & Medicamentos & Vacinas \\
\hline $\begin{array}{l}\text { Instituto de Tecnologia de } \\
\text { Imunobiológicos (Bio- } \\
\text { Manguinhos) }\end{array}$ & $\begin{array}{l}\text { Rio de } \\
\text { Janeiro }\end{array}$ & 0 & 3 & 0 & 3 \\
\hline $\begin{array}{l}\text { Centro de Pesquisas Aggeu } \\
\text { Magalhães (CPqAM) }\end{array}$ & Recife & 0 & 1 & 0 & 1 \\
\hline $\begin{array}{l}\text { Centro de Pesquisas Gonçalo } \\
\text { Muniz (CPqGM) }\end{array}$ & Salvador & 0 & 1 & 2 & 0 \\
\hline $\begin{array}{l}\text { Centro de Pesquisas Leônidas e } \\
\text { Maria Deane (CPqLMD) }\end{array}$ & Manaus & 0 & 1 & 0 & 0 \\
\hline $\begin{array}{l}\text { Centro de Pesquisas René } \\
\text { Rachou (CPqRR) }\end{array}$ & $\begin{array}{c}\text { Belo } \\
\text { Horizonte }\end{array}$ & 1 & 2 & 1 & 2 \\
\hline $\begin{array}{l}\text { Instituto de Tecnologia em } \\
\text { Fármacos (Farmanguinhos) }\end{array}$ & $\begin{array}{l}\text { Rio de } \\
\text { Janeiro }\end{array}$ & 0 & 0 & 11 & 0 \\
\hline $\begin{array}{l}\text { Instituto de Biologia Molecular } \\
\text { do Paraná (IBMP) }\end{array}$ & Curitiba & 0 & 2 & 0 & 0 \\
\hline Instituto Oswaldo Cruz (IOC) & $\begin{array}{l}\text { Rio de } \\
\text { Janeiro }\end{array}$ & 8 & 8 & 3 & 8 \\
\hline $\begin{array}{l}\text { Instituto de Pesquisa Clínica } \\
\text { Evandro Chagas (Ipec) }\end{array}$ & $\begin{array}{l}\text { Rio de } \\
\text { Janeiro }\end{array}$ & 0 & 1 & 0 & 1 \\
\hline
\end{tabular}

Fonte: VPPDT, 2006.

rência Geral do PDTIS em torno de cada uma das redes. As reuniões contam com a participação dos coordenadores da rede, da Coordenação Geral do PDTIS, dos gestores da VPPDT e de consultores externos à Fiocruz responsáveis pela análise técnico-científica do desenvolvimento dos projetos. Conforme estabelecido na carta-compromisso e no Manual de organização do PD$T I S^{23}$, no final da avaliação o projeto pode ser desligado do programa. Os dados listados na Tabela 2 não contemplam projetos descontinuados após a realização das reuniões de avaliação das redes cooperativas entre agosto e novembro de 2007.

Quanto à estrutura organizacional, o PDTIS possui duas instâncias: o Núcleo Gestor e a Coordenação de Redes Cooperativas, representadas na Figura 1.

Em 2003²3, integravam o Núcleo Gestor a Coordenação Geral, os consultores externos à Fiocruz, o Apoio Administrativo e as seguintes gerências: Geral; Técnico-Científica; Propriedade Intelectual e Parcerias; Planejamento Estratégico; Orçamentária. Em termos de atribuições e competências, cabe ao Núcleo Gestor analisar, selecionar e acompanhar técnica e economicamente todos os projetos, gerando procedimentos que permitam sua implementação e o gerenciamento
Tabela 2. Número de projetos por rede cooperativa em 2007.

\begin{tabular}{lc}
\hline \multicolumn{1}{c}{ Redes } & $\begin{array}{c}\text { Número de } \\
\text { projetos }\end{array}$ \\
\hline Genômica e Proteômica Aplicada & 09 \\
Insumos Diagnósticos & 22 \\
Medicamentos & 18 \\
Vacinas & 17 \\
Total & $\mathbf{6 6}$ \\
\hline
\end{tabular}

Fonte: Relatório de Gestão da Fiocruz, 2007.

das redes cooperativas em que estejam inseridos ${ }^{23}$. A Coordenação Geral visa coordenar e viabilizar a implantação e a implementação das ações do Núcleo Gestor, enquanto à Gerência Geral cabe estruturar, implementar ações entre as redes cooperativas e estabelecer procedimentos visando à organização das redes em concordância com os requisitos de qualidade $e^{23}$.

Em 2006 ${ }^{24}$, a composição do Núcleo Gestor foi alterada. Identificamos a inclusão dos coordenadores das redes cooperativas e da rede de plataformas tecnológicas, assessores da VPPDT, além de três consultores técnico-científicos da Fiocruz, dos quais dois são vinculados às unida- 


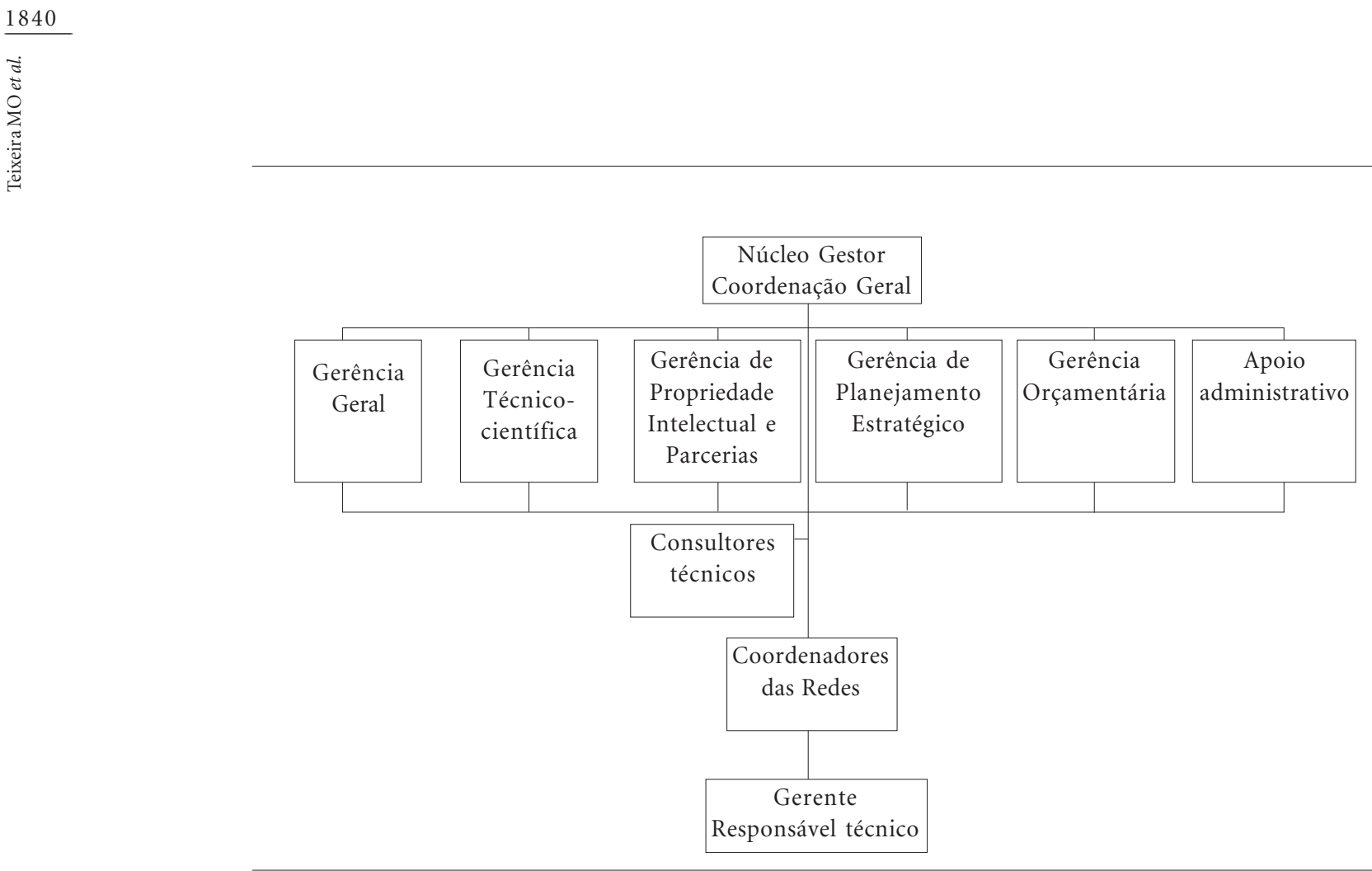

Figura 1. Organograma do PDTIS.

Fonte: Manual de organização do PDTIS ${ }^{23}$.

des de produção e um ao futuro Centro de Desenvolvimento Tecnológico (CDTS), e a exclusão dos consultores externos. Um ano depois, a composição do Núcleo Gestor é alterada novamente com a saída dos assessores da VPPDT.

A Coordenação das Redes Cooperativas não sofreu mudanças desde 2002, com a forte presença do IOC na coordenação das Redes de Insumos Diagnósticos e de Genômica Aplicada e Proteômica e das Unidades de Produção nas Redes de Vacinas e de Medicamentos e Bioinseticidas.

Quanto à organização das redes, cada uma conta com um coordenador, um gerente por projeto e um ou no máximo dois responsáveis técnicos. As atribuições dos coordenadores de rede, gerentes e responsáveis técnicos foram estabelecidas na primeira versão do Manual de organização do PDTIS em $2003^{23}$, o qual prescreve todo o funcionamento do programa. Em $2004^{21}$, houve pequenas correções na forma, mas sem mudanças de conteúdo. Utilizaremos a versão de 2004 como referência para o restante do artigo. É importante registrar que desde 2006 o Manual está em revisão e foi retirado do sítio da VPPDT.

Quanto às atribuições, compete: (1) ao coordenador de rede, realizar reuniões periódicas com os gerentes dos projetos para avaliação dos re- sultados; garantir o cumprimento das normas de qualidade em todas as fases do projeto; solicitar avaliação dos consultores técnicos; (b) à gerência do projeto, o cumprimento das metas estabelecidas, o acompanhamento do cronograma físico-financeiro; é responsável pela elaboração e guarda da documentação e dos registros de qualidade $^{21}$.

\section{Dinâmica das redes cooperativas}

O que se segue é fruto da sistematização e análise dos dados obtidos por meio das entrevistas com gestores do PDTIS, coordenadores de rede e, sobretudo, gerentes de projetos, além da observação das reuniões e da análise documental. Identificamos duas formas de agrupamentos dos atores da pesquisa: (1) as reuniões do Núcleo Gestor, relacionadas à gestão do programa; (2) as reuniões de avaliação. As redes cooperativas não promoveram, até junho de 2008, nenhuma forma de interação entre os pesquisadores.

No intuito de conhecer e caracterizar a dinâmica das redes cooperativas do PDTIS, privilegiamos as seguintes variáveis estruturantes da descrição e análise: (1) as relações entre as diferentes 
instâncias da estrutura do PDTIS; (2) as formas e os mecanismos de interação entre as equipes de pesquisa de uma determinada rede; (3) a presença de ferramentas de tecnologia da informação e comunicação que intensificam a colaboração no interior de uma rede ou entre as redes cooperativas; (4) o compartilhamento da base técnico-científica no interior de uma rede ou entre as redes cooperativas.

Em 2002 as redes cooperativas foram tomadas como modelo de organização da pesquisa tecnológica que permite a colaboração "entre os participantes de forma não competitiva" e a convivência de iniciativas de pesquisa tecnológica em "quaisquer das etapas previstas no desenvolvimento tecnológico" de insumos em saúde ${ }^{15}$. Quatro anos depois, lemos que o modelo adotado de estruturação em redes cooperativas visa aproximar pesquisadores para trabalhar de forma cooperativa em torno de objetivos comuns e de tecnologias similares e otimizar recursos humanos e financeiros $^{24}$. O propósito das redes cooperativas é promover: (1) o intercâmbio de protocolos e de procedimentos técnicos; (2) o treinamento e a interação entre os grupos ativos na Fiocruz; (3) o suprimento de infraestrutura e apoio técnico ${ }^{21}$.

As quatro redes do PDTIS (Vacinas, Medicamentos e Bioinseticida, Genômica e Proteômica, Insumos Diagnósticos) foram constituídas a partir da análise das cartas de intenção enviadas por equipes de pesquisa das unidades da Fiocruz. Em 2002, parte expressiva das cartas originou-se de projetos em desenvolvimento, alguns financiados por agências nacionais, como o Conselho Nacional de Desenvolvimento Científico e Tecnológico (CNPq). Em 2006, o programa lançou editais para submissão de novas propostas para as Redes de Insumos para Diagnóstico, de Medicamentos e Bioinseticidas e de Vacinas.

Para compreendermos a dinâmica das redes, recorremos ao Manual de organização do PD$T_{I S^{21,23}}$ e às entrevistas com os coordenadores, gerentes e responsáveis técnicos. O Manual estabelece os fluxos de informações, define os níveis de competências para tomada de decisão e as rotinas gerenciais para as diferentes instâncias da estrutura organizacional do PDTIS.

O Quadro 1 retrata uma estrutura hierarquizada, com decisões centralizadas no Núcleo Gestor e com um alto volume de informes, pareceres, solicitações, relatórios técnicos e autorizações. Todavia, nas entrevistas com os coordenadores de redes e com os gerentes de projetos, as atribuições e responsabilidades não apareceram com a mesma clareza. Quando solicitamos que descre- vessem as responsabilidades e as atribuições das diferentes instâncias do PDTIS, os entrevistados, em sua maioria, apresentaram dificuldades em fazê-lo. Os gerentes de projetos, em especial, encontravam dificuldades em descrever com precisão o fluxo de informações e a cadeia de tomada de decisão do programa. Os entrevistados descreviam com mais facilidade as atribuições da Coordenação Geral do PDTIS, indicada como espaço das decisões sobre a gestão tecnológica do programa, seleção de consultores, abertura de novos editais para seleção de projetos, descontinuidade de apoio a projetos, além de aprovação e remanejamento de orçamento. Nesse sentido, quando concentramos nossa análise nos depoimentos, as atribuições da Coordenação Geral parecem se confundir com as do Núcleo Gestor.

É importante observar que o Manual coloca o coordenador de rede frequentemente nas posições de mediador (solicita informações ao gerente e encaminha ao Núcleo Gestor) e de executor das decisões tomadas pelo Núcleo Gestor.

Uma responsabilidade central e, segundo o Manual, exclusiva do coordenador de rede é o acompanhamento técnico dos projetos. Entretanto, durante a observação das reuniões de avaliação, constatamos problemas nesse acompanhamento. Os relatórios técnicos só são solicitados no momento da reunião de avaliação, quando os gerentes são interpelados pelos consultores externos. Os gerentes entrevistados não discutiam os problemas e relatórios técnicos com os coordenadores de rede fora das reuniões de avaliação. Durante nossa observação das reuniões de avaliação, registramos que alguns coordenadores não detinham informações atualizadas dos projetos de sua rede. Não raro, os gerentes apresentavam problemas ou soluções tomadas nos últimos meses desconhecidas dos coordenadores de rede.

Quanto à diversidade de interações características ${ }^{3,8}$ das equipes de pesquisa organizadas em redes (colaborações, permuta de insumos, uso compartilhado de equipamentos), constatamos, nas entrevistas e durante a observação das reuniões de avaliação, que são tímidas. Até o momento, não identificamos colaborações técnicocientíficas expressivas entre as equipes de pesquisa de uma mesma rede. Como as redes abrigam projetos anteriores a sua criação e equipes de pesquisa já estabelecidas, grande parte das colaborações técnico-científicas identificadas já existia. Algumas, inclusive, em torno de projetos financiados por agências de fomento à pesquisa. Há exceções, mas até onde conseguimos apurar, poucas colaborações surgiram como efeito das redes. 
Quadro 1. Responsabilidades do Núcleo Gestor, dos coordenadores de rede e dos gerentes.

\begin{tabular}{|c|c|c|}
\hline Núcleo Gestor & Coordenadores de rede & Gerente de projeto \\
\hline $\begin{array}{l}\text { Aprovar os recursos orçamentários } \\
\text { que serão repassados aos projetos. }\end{array}$ & $\begin{array}{l}\text { Acompanhar tecnicamente o projeto através dos } \\
\text { relatórios técnicos enviados pelo gerente de } \\
\text { projeto. }\end{array}$ & $\begin{array}{l}\text { Coordenar, através dos } \\
\text { responsáveis técnicos, a atividade } \\
\text { proposta. }\end{array}$ \\
\hline $\begin{array}{l}\text { Acompanhar tecnicamente e } \\
\text { administrativamente o projeto. }\end{array}$ & $\begin{array}{l}\text { Fazer questionamentos ao gerente de projeto sobre } \\
\text { a execução do projeto sempre que as informações } \\
\text { presentes no relatório técnico não se apresentarem } \\
\text { suficientes, ou em qualquer outra situação em que } \\
\text { tais esclarecimentos se fizerem necessários. }\end{array}$ & $\begin{array}{l}\text { Acompanhar tecnicamente o } \\
\text { projeto. }\end{array}$ \\
\hline $\begin{array}{l}\text { Solicitar ao coordenador de rede o } \\
\text { cumprimento dos objetivos, metas } \\
\text { e prazos estabelecidos no projeto. }\end{array}$ & $\begin{array}{l}\text { Encaminhar os relatórios técnicos, juntamente } \\
\text { com seu parecer sobre a execução do projeto, ao } \\
\text { Núcleo Gestor. }\end{array}$ & $\begin{array}{l}\text { Solicitar de cada responsável } \\
\text { técnico o cumprimento de } \\
\text { objetivos, metas e prazos } \\
\text { estabelecidos no projeto. }\end{array}$ \\
\hline $\begin{array}{l}\text { Decidir sobre a interrupção da } \\
\text { execução do projeto. }\end{array}$ & $\begin{array}{l}\text { Responder, perante o Núcleo Gestor, pelo } \\
\text { cumprimento das normas de qualidade em todas } \\
\text { as fases de execução do projeto. }\end{array}$ & $\begin{array}{l}\text { Zelar pelo atendimento às Boas } \\
\text { Práticas de Laboratório. }\end{array}$ \\
\hline $\begin{array}{l}\text { Decidir, no momento oportuno, } \\
\text { sobre a estratégia e a forma de } \\
\text { proteção e exploração dos } \\
\text { resultados obtidos pela execução } \\
\text { do projeto. }\end{array}$ & $\begin{array}{l}\text { Solicitar do gerente de projeto o cumprimento dos } \\
\text { objetivos, metas e prazos estabelecidos no projeto. }\end{array}$ & $\begin{array}{l}\text { Zelar pela manutenção de sigilo } \\
\text { sobre as informações e resultados } \\
\text { das atividades desenvolvidas. }\end{array}$ \\
\hline $\begin{array}{l}\text { Deliberar quanto à possibilidade e } \\
\text { condições de divulgação das } \\
\text { informações confidenciais. }\end{array}$ & $\begin{array}{l}\text { Informar ao Núcleo Gestor sobre todas as parcerias } \\
\text { vinculadas à execução do projeto já existentes quando } \\
\text { da celebração da carta-compromisso, formalizadas } \\
\text { ou não, quando assim lhe for solicitado. }\end{array}$ & $\begin{array}{l}\text { Fazer o levantamento e informar } \\
\text { ao coordenador de rede sobre } \\
\text { todas as parcerias vinculadas à } \\
\text { execução do projeto já existentes } \\
\text { quando da celebração da carta- } \\
\text { compromisso. }\end{array}$ \\
\hline $\begin{array}{l}\text { Solicitar ao coordenador de rede } \\
\text { informações sobre todas as } \\
\text { parcerias vinculadas à execução do } \\
\text { projeto já existentes, formalizadas } \\
\text { ou não, quando da celebração da } \\
\text { carta-compromisso. }\end{array}$ & $\begin{array}{l}\text { Analisar e encaminhar, com seu parecer sobre o } \\
\text { assunto, ao Núcleo Gestor a solicitação do gerente } \\
\text { de projeto do estabelecimento de qualquer nova } \\
\text { parceria a ser celebrada para a execução do projeto. }\end{array}$ & $\begin{array}{l}\text { Não estabelecer ou autorizar a } \\
\text { celebração de novas parcerias para } \\
\text { a execução do projeto sem a } \\
\text { devida formalização e aprovação } \\
\text { do coordenador de rede, a qual } \\
\text { deverá ser solicitada através de } \\
\text { manifestação que aponte as } \\
\text { vantagens, o interesse e a } \\
\text { necessidade da celebração delas. }\end{array}$ \\
\hline $\begin{array}{l}\text { Deliberar e autorizar ao } \\
\text { coordenador de rede deliberar } \\
\text { sobre a possibilidade e as } \\
\text { condições do estabelecimento de } \\
\text { qualquer nova parceria } \\
\text { estabelecida para a execução do } \\
\text { projeto, a ser celebrada após a } \\
\text { assinatura da carta-compromisso. }\end{array}$ & $\begin{array}{l}\text { Autorizar o gerente de projeto a estabelecer novas } \\
\text { parcerias a serem celebradas para a execução do } \\
\text { projeto, caso aprovado pelo Núcleo Gestor e nas } \\
\text { condições por ele estabelecidas. }\end{array}$ & $\begin{array}{l}\text { Não enviar nem permitir o envio } \\
\text { ou o recebimento de qualquer } \\
\text { amostra de material biológico sem } \\
\text { a devida formalização e aprovação } \\
\text { do coordenador de rede, a qual } \\
\text { deverá ser solicitada através de } \\
\text { manifestação que aponte sobre } \\
\text { razões, o interesse e a necessidade } \\
\text { da realização do envio. }\end{array}$ \\
\hline
\end{tabular}


Quadro 1. continuação

\begin{tabular}{|c|c|c|}
\hline Núcleo Gestor & Coordenadores de rede & Gerente de projeto \\
\hline $\begin{array}{l}\text { Deliberar e autorizar ao } \\
\text { coordenador de rede deliberar } \\
\text { sobre a possibilidade e as } \\
\text { condições de envio de material } \\
\text { biológico efetivado após a } \\
\text { celebração da carta-compromisso, } \\
\text { quando realizado em razão da } \\
\text { execução do projeto. }\end{array}$ & $\begin{array}{l}\text { Analisar e encaminhar, com seu parecer sobre o } \\
\text { assunto, ao Núcleo Gestor a solicitação do gerente } \\
\text { de projeto de autorização do envio de material } \\
\text { biológico a ser realizado em razão da execução do } \\
\text { projeto. }\end{array}$ & $\begin{array}{l}\text { Coordenar a elaboração de } \\
\text { relatórios técnicos periódicos e } \\
\text { detalhados a respeito do } \\
\text { andamento das ações previstas, } \\
\text { conforme estabelecido no projeto, } \\
\text { e enviar ao coordenador de rede. }\end{array}$ \\
\hline $\begin{array}{l}\text { Solicitar ao gerente de projeto o } \\
\text { cumprimento do cronograma } \\
\text { físico-financeiro. }\end{array}$ & $\begin{array}{l}\text { Autorizar o gerente de projeto para a realização do } \\
\text { envio de material biológico, a ser procedido em } \\
\text { decorrência da execução do projeto, caso aprovado } \\
\text { pelo Núcleo Gestor e nas condições por ele } \\
\text { estabelecidas. }\end{array}$ & $\begin{array}{l}\text { O atendimento do cronograma } \\
\text { físico-financeiro e a prestação de } \\
\text { contas ao Núcleo Gestor. }\end{array}$ \\
\hline $\begin{array}{l}\text { Informar ao coordenador da rede } \\
\text { sobre o cumprimento do } \\
\text { cronograma físico-financeiro do } \\
\text { projeto. }\end{array}$ & $\begin{array}{l}\text { Solicitar a avaliação de consultores técnicos para } \\
\text { auxiliar no alcance dos objetivos do projeto e no } \\
\text { atendimento das normas de qualidade, se entender } \\
\text { necessário. }\end{array}$ & $\begin{array}{l}\text { Solicitar, através do coordenador } \\
\text { de rede ao Núcleo Gestor, a } \\
\text { alteração quantitativa dos recursos } \\
\text { destinados ao projeto pelo PDTIS. }\end{array}$ \\
\hline $\begin{array}{l}\text { Fiscalizar a adequação do } \\
\text { cronograma físico-financeiro ao } \\
\text { destino efetivo dos recursos } \\
\text { disponibilizados pelo PDTIS para } \\
\text { execução do projeto. }\end{array}$ & $\begin{array}{l}\text { Analisar a solicitação de alteração quantitativa dos } \\
\text { recursos destinados ao projeto realizada pelo } \\
\text { gerente de projeto e encaminhá-la ao Núcleo } \\
\text { Gestor para apreciação. }\end{array}$ & \\
\hline
\end{tabular}

Fonte: Manual de organização do PDTIS ${ }^{23}$.

Quanto às colaborações externas à Fiocruz, o Manual de organização ${ }^{21}$ estabelece restrições sem que antes haja a aprovação do coordenador de rede e do Núcleo Gestor. É importante salientar que nas unidades de pesquisa da Fiocruz, inclusive naquelas que participam das redes cooperativas, o estabelecimento de parcerias formais intra e extramuros é uma atribuição do chefe de laboratório, com baixíssima regulação.

Outra frente são as colaborações com o setor produtivo da saúde. Segundo os relatórios de atividades do PDTIS ${ }^{20,24}$, algumas equipes de pesquisa estabeleceram parcerias com indústrias privadas e públicas interessadas no repasse de tecnologias ou para a prestação de serviços tecnológicos. Nas entrevistas com a Coordenação e a Gerência do PDTIS, essas parcerias foram consideradas por ambas como o primeiro fruto da gestão tecnológica do programa. Observamos, todavia, que os relatórios nem sempre deixam claro o objeto da parceria. Durante as reuniões de avaliação, constatamos que muitas se destinam à prestação de serviços tecnológicos aos projetos e foram recomendadas pelos consultores.

A metodologia dessas reuniões reforça a timidez das interações entre as equipes de pesquisa no interior das redes cooperativas. Em 2007, houve uma mudança na metodologia das reuniões. Antes, os gerentes e responsáveis técnicos assistiam a análise de todos os projetos da rede. A partir de 2007, os consultores, coordenadores de rede e membros do Núcleo Gestor (Coordenação Geral, Gerência Geral) passaram a se reunir separadamente com cada equipe de projeto. Alguns gerentes entrevistados aprovaram a nova metodologia, destacando o maior tempo para aprofundarem o diálogo com os consultores e a maior privacidade. Outros mencionaram desconforto com a discussão de seus projetos diante de todos os gerentes de projetos e, em alguns casos, dos responsáveis técnicos. Um ponto recorrente nas falas é que na metodologia anterior não ocorria, em geral, a participação ativa dos demais gerentes e/ou responsáveis técnicos na discussão dos pro- 
jetos. Cada equipe manifestava-se apenas quando seu projeto estava em foco. Não houve menção, por parte dos gerentes e coordenadores, do uso de estratégias para estimular maior participação de todos os presentes. No entanto, como os gerentes e os responsáveis técnicos não têm acesso a todos os relatórios técnicos, conheciam pouco sobre os demais projetos da sua rede.

A Rede de Genômica e Proteômica Aplicada, por sua vez, manteve a metodologia anterior. Realizamos uma observação durante a reunião de 2007. Destacamos a seguir alguns pontos que corroboram os depoimentos anteriores: (1) embora a presença de todos fosse não apenas permitida, mas desejada, alguns gerentes não compareceram; (2) alguns gerentes e responsáveis técnicos saíram assim que a discussão de seus projetos foi concluída; apenas uma gerente participou ativamente de todas as discussões; (3) somente a equipe se manifestava enquanto o consultor externo analisava o projeto; (4) a Coordenação da Rede de Plataformas, responsável pelo gerenciamento de muitos equipamentos utilizados pelos projetos em discussão, não participou de toda a reunião.

Um ponto considerado positivo pela coordenação geral do PDTIS e pela VPPDT é a sua proximidade com os institutos de produção da Fiocruz de imunobiológicos e de medicamentos. Até o final do século XX, as relações de colaboração entre as unidades de produção e as unidades de pesquisa técnico-científica da Fiocruz eram fortuitas. Maior aproximação é registrada nos últimos sete anos, em especial na área de insumos diagnósticos em saúde. No entanto, até o momento as interações das redes cooperativas repetem o padrão observado para as demais equipes de pesquisa, ou seja, as mais intensas são anteriores à existência das redes. Identificamos quatro formas de participação das unidades de produção nas redes: (1) projetos desenvolvidos por equipes de pesquisa dos institutos de produção; (2) projetos desenvolvidos por equipes de pesquisa com as quais os institutos mantêm colaborações; (3) participação na coordenação das redes de Vacinas e Medicamentos; (4) participação nas reuniões de avaliação da Rede de Insumos Diagnósticos. É interessante frisar que na situação "2" a maioria das colaborações analisadas foi constituída antes do PDTIS.

Quando observarmos a infraestrutura que está associada a cada uma das redes, constatamos que o compartilhamento de equipamentos, insumos e equipes de pesquisa pelos projetos organizados em uma mesma rede enfrenta difi- culdades. Os equipamentos utilizados pelos projetos foram adquiridos por um mix de recursos. Parte foi financiada por projetos de pesquisa individuais, parte com recursos orçamentários da unidade (à qual pertence o grupo de pesquisa) e uma parte pelo PDTIS. Ou seja, além dos equipamentos adquiridos para a Rede de Plataformas, o PDTIS financiou a aquisição de equipamentos específicos para os projetos. Encontramos o mesmo mecanismo para a aquisição de insumos (soluções, reagentes e kits para experimentos). Constatamos nas entrevistas e ao longo da observação das reuniões que o compartilhamento de equipamentos e reagentes ocorre entre equipes que já mantinham colaboração anterior ao PDTIS. No entanto, não identificamos em nenhuma instância (Coordenação Geral, Gerência Geral, coordenações de redes) o uso de ferramentas de tecnologia da informação e comunicação (TIC) para agilizar ou criar fluxos de informação e comunicação entre as redes, capaz de facilitar o uso compartilhado de um insumo, permutas e empréstimos de equipamento e reagentes. Não identificamos listagens de insumos de uso comum ou registro de sobras de insumos disponíveis para consulta de gerentes ou dos coordenadores de rede; o mesmo em relação aos equipamentos que não pertencem à Rede de Plataformas. As listagens de equipamentos e, sobretudo, as de insumos comuns não estão acessíveis aos coordenadores de rede em razão da forma como o orçamento do programa é elaborado. O orçamento não é elaborado e discutido coletivamente no interior da rede cooperativa; cada gerente elabora seu orçamento, encaminha ao coordenador para pré-análise e ao núcleo gestor. As compras autorizadas são realizadas em parte pela gerência orçamentária do PDTIS e, em parte, pelas unidades da Fiocruz. Assim, o orçamento e as compras não são consolidados por rede cooperativa, mas por projeto ${ }^{25}$.

O Manual de organização $o^{21}$ define como responsabilidade do Núcleo Gestor a aprovação dos recursos orçamentários, além do exercício de fiscalização da sua posterior execução. Nas entrevistas realizadas com os coordenadores de rede, essa responsabilidade foi deslocada para a Coordenação Geral, havendo, portanto, uma coordenação centralizada. Os coordenadores de rede apreciam as solicitações, são consultados sobre eventuais cortes, mas a decisão cabe ao Coordenador Geral, principal interlocutor da gerência orçamentária e da Presidência da Fiocruz. Entre os gerentes de projetos entrevistados, havia pouca clareza a respeito dos critérios utilizados e das 
interações entre as diferentes instâncias para a deliberação do orçamento.

\section{Conclusão}

Não obstante o desmesurado sucesso no Brasil das redes cooperativas como instrumento de coordenação da pesquisa científica e tecnológica junto às agências de fomento, carecemos de estudos empíricos sobre a apropriação desse instrumento em diferentes contextos sócio-históricos de produção de conhecimentos técnico-científicos, particularmente no campo da saúde. Nossa contribuição consistiu em compreender o uso das redes cooperativas em uma instituição pública de pesquisa em saúde (Fiocruz) tomando o PDTIS como referência empírica. A síntese apresentada a seguir tem caráter exploratório, de primeira confrontação do material empírico com a literatura internacional especializada nas redes de pesquisa cooperativa ${ }^{3,5-10,12,14,21,23,26,27}$.

Confrontando a literatura ${ }^{3,5,6,10} \mathrm{com}$ as entrevistas realizadas, em especial com os gerentes de projetos, e com as observações das reuniões de avaliação, tomamos o PDTIS como programa de indução que utiliza instrumentos relacionados à pesquisa colaborativa (redes, reuniões de avaliação, consultores externos e relatório de acompanhamento), mas não como indução à pesquisa colaborativa.

Segundo a literatura ${ }^{5,6,10,14}$, a pesquisa colaborativa ocorre entre multi-instituições e envolve atores agindo de forma multi e interdisciplinar. Katz e Martin ${ }^{14}$ incluem as colaborações entre departamentos de uma instituição (colaboração intra-institucional $\left.{ }^{6,14}\right)$. Mas um ponto comum à literatura é o centramento das colaborações em um tema ou objeto em torno do qual se

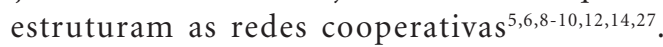
Também enfatiza-se a divisão de trabalho entre as equipes de pesquisa de uma mesma rede ou programa para caracterizar a pesquisa colaborativa $^{5,6,8,9,12,14}$. A divisão de trabalho distingue a pesquisa colaborativa de interações pontuais entre equipes ${ }^{8,27}$, mesmo nas colaborações intrainstitucionais ${ }^{6,14}$.

Constatamos, a partir da entrevistas, que os projetos no PDTIS não estão articulados entre si. Logo, não há divisão de trabalho entre equipes. Outro elemento relacionado à formação de colaborações pela literatura ${ }^{5,6,8-10,12,14}$, o compartilhamento de equipamentos e de expertise técnico-científica, não pode ser facilmente relacionado às redes. Os casos identificados eram anterio- res ao PDTIS e à formação das redes. Portanto, as entrevistas complementadas com a observação empírica das reuniões de avaliação nos permitem afirmar que o programa ainda não logrou a construção do trabalho cooperativo entre equipes associadas em redes.

Segundo a literatura ${ }^{6,7,9,14,27}$, a transferência de tecnologia entre as equipes de pesquisa é responsável em grande medida pela disseminação das colaborações. Por intermédio das observações empíricas, concluímos que a dinâmica das redes não favorece o compartilhamento de soluções técnicas, coibindo a transferência de tecnologia. A dinâmica das reuniões de avaliação exemplifica a falta de articulação e a inexistência de problemática ou tecnologia ${ }^{7}$ comum à rede. A reunião privilegia objetivos e metas individuais, demonstrando que no PDTIS estamos diante de um discurso novo de gestão de C\&T, mas sem enraizamento no corpo social dos pesquisadores, e de uma prática tradicional de coordenação da pesquisa, efetivamente enraizada na instituição.

O financiamento também é centrado na análise dos projetos individuais, enquanto nos casos analisados pela literatura os recursos são distribuídos a partir da divisão de trabalho entre as equipes $^{7,14,27}$.

As redes cooperativas, em geral, são associadas às estruturas flexíveis e horizontais ${ }^{3,4}$. Entretanto, Shrum et al. ${ }^{3}$ registram a associação de redes cooperativas com estruturas verticais e hierarquizadas. Todavia, no caso do PDTIS o desconhecimento das regras e da dinâmica entre as diferentes instâncias, manifestado nas entrevistas com gerentes de projeto, termina por comprometer o fortalecimento da capacidade de coordenação associada às redes cooperativas.

A literatura aponta as ferramentas de comunicação e informação como essenciais à divisão de trabalho entre equipes e ao acompanhamento de metas ${ }^{7,8,10}$. Ao longo das entrevistas e da observação empírica, não identificamos no PDTIS a presença de ferramentas para comunicação e gestão da informação entre equipes dos projetos, apenas instrumentos para gestão da informação pela Coordenação Geral, Gerência e consultores. Isso reforça a inexistência de divisão de trabalho entre as equipes de uma mesma rede.

Em síntese, as redes cooperativas do PDTIS convivem com um modo de organização da pesquisa centrado em projetos individuais. Elas são utilizadas para a coordenação de projetos individuais, em lugar de equipes em diferentes atividades de um projeto comum ou nos seus subprojetos, o que as torna, assim, um estudo de caso 
singular na constelação analisada pela literatura internacional. Porém, desempenharam uma posição relevante no processo de organização da pesquisa, reunindo equipes de pesquisa e projetos individuais antes dispersos pelas unidades da Fiocruz.

Aspectos fundamentais para os objetivos do PDTIS, como o aumento da regulação de parcerias, a sistemática de avaliação de projetos e o diálogo entre unidades de pesquisa e produção, prescindiram da ação das redes. Trata-se de um conjunto de ações em processo de implantação, realizadas por outras instâncias do programa (Coordenação Geral, Gerência Geral e Gestão Tecnológica).

\section{Colaboradores}

MO Teixeira, CJS Machado, ATP Filipecki, BA Cortes e HE Klein participaram igualmente de todas as etapas da pesquisa e da elaboração do artigo.

\section{Agradecimentos}

Ao Conselho Nacional de Desenvolvimento Científico e Tecnológico $(\mathrm{CNPq})$ o apoio para a realização da pesquisa Inovação em Saúde Pública: estudo de caso do processo de construção social, coletivo e local da Rede Vacinas Recombinantes e DNA da Fundação Oswaldo Cruz, que resultou neste artigo. 


\section{Referências}

1. Ferrer M, Thorsteinsdóttir H, Quach U, Singer PA, Daar AS. The scientific muscle of Brazil's health biotechnology. Nature Biotechnology 2002; 22(Suppl.): DC8-DC12.

2. Guimarães RF. A pesquisa médica e biomédica no Brasil: comparações com o desempenho científico brasileiro e mundial. Cien Saude Colet 2004; 9(2):303327.

3. Shrum W, Genuth J, Chompalov I. Structures of scientific collaboration. Cambridge: The MIT Press; 2007.

4. Callon M, Larédo P, Mustar P. La gestion stratégique de la recherche et de la technologie: l'évaluation des programmes. Paris: Economica; 1995.

5. Chompalov I, Shrum W. Institutional collaboration in science: a typology of technological practice. Science, Technology \& Human Values 1999; 24(3):338-372.

6. Larsen K. Knowledge network hubs and measures of research impact, science structure and publication output in nanostructured solar cell research. Scientometrics 2008; 74(1):123-142.

7. Pirró e Longo W, Oliveira ARP. Pesquisa cooperativa e centros de excelência. Parcerias Estratégicas 2000; 9:129-144.

8. Beaver DB. Refletions on scientific collaboration (and its study): past, present and future. Scientometrics 2001; 52(3):365-377.

9. Beaver DB. Teamwork: a step beyond collaboration. In: George Sarton Centennial, Communication and Cognition. Ghent, Belgium; 1984. p. 449-452.

10. Cummings J, Kiesler S. Collaborative research across disciplinary and organizational boundaries. Social Studies of Science 2005; 35(5):703-722.

11. Chen C. Mapping scientific frontiers: the quest for knowledge visualization. London: Springer; 2003.

12. Sonnenwald D. The conceptual organization: an emergent organizational form for collaborative R\&D. Science and Public Policy 2003; 30(4):261-272.

13. Denzin NK, Lincoln YS. The SAGE handbook of qualitative research. $3^{\text {rd }}$ ed. London: Sage; 2005.

14. Katz JS, Martin B. What is research collaboration? Research Policy 1997; 26:1-8.

15. Brasil. Fundação Oswaldo Cruz. Programa de Desenvolvimento Tecnológico em Insumos em Saúde (PDTIS). Rio de Janeiro: Fiocruz; 2002. p. 1-84. (mimeo).

16. Associação Brasileira de Pós-Graduação em Saúde Coletiva (Abrasco). Política Nacional de Ciência, Tecnologia e Inovação em Saúde: uma proposta. Rio de Janeiro: Abrasco; 2002. p. 1-50. (mimeo).
17. Guimarães JA. A pesquisa médica e biomédica no Brasil: comparações com o desempenho científico brasileiro e mundial. Cien Saude Colet 2004; 9(2):303327.

18. Brasil. Ministério de Ciência e Tecnologia. Ciência e tecnologia e inovação: desafios para a sociedade brasileira (livro verde). Brasília: Ministério de Ciência e Tecnologia/Academia Brasileira de Ciências; 2001.

19. Buss PM, Temporão JG, Carvalheiro JR, organizadores. Vacinas, soros e imunizações no Brasil. Rio de Janeiro: Editora Fiocruz; 2005.

20. Brasil. Fundação Oswaldo Cruz. Relatório de gestão. Rio de Janeiro: Fiocruz; 2007. (mimeo).

21. Brasil. Fundação Oswaldo Cruz. Manual de organização do PDTIS. Rio de Janeiro: Fiocruz; 2004. (mimeo).

22. Morel CM, Carvalheiro JR, Romero CN, Costa EA, Buss PM. The road to recovery. Nature 2007; 449:180182.

23. Brasil. Fundação Oswaldo Cruz. Manual de organização do PDTIS. Rio de Janeiro: Fiocruz; 2003. (mimeo).

24. Brasil. Fundação Oswaldo Cruz. Relatório de atividades da Fundação Oswaldo Cruz. Rio de Janeiro: Fiocruz; 2006. (mimeo).

25. Bezerra CS. Gerenciamento de portfólio de projetos de P\&D: um estudo sobre o Programa de Desenvolvimento Tecnológico em Insumos para a Saúde (PDTIS) [dissertação]. Rio de Janeiro: Escola Nacional de Saúde Pública Sergio Arouca, Fundação Oswaldo Cruz; 2008.

26. Brasil. Fundação Oswaldo Cruz. Plano quadrienal. Rio de Janeiro: Fiocruz; 2005. (mimeo).

27. Smith D, Katz JS. Collaborative approaches to research: final report. HEFCE Fundamental Review of Research Policy and Funding. Brighton, UK: University of Sussex; 2000.

Artigo apresentado em 15/08/2008

Aprovado em 15/01/2009

Versão final apresentada em 23/01/2009 